\title{
Social economic factors and malaria transmission in Lower Moshi, Northern Tanzania
}

\author{
Asanterabi Lowassa ${ }^{1 *}$, Humphrey D Mazigo ${ }^{2}$, Aneth M Mahande ${ }^{3}$ Beda J Mwang'onde ${ }^{3}$, Shandala Msangi ${ }^{3}$, \\ Michael J Mahande ${ }^{4}$, Epiphania E Kimaro ${ }^{3}$, Eliapenda Elisante ${ }^{5}$ and Eliningaya J Kweka ${ }^{2,3}$
}

\begin{abstract}
Background: For many years social economic status has been used as an indicator to characterize malaria treatment seeking behaviors of communities and their adherence to malaria control programs. The present study was therefore conducted to assess the influence of household social economic status, knowledge, attitude and practice on treatment seeking behaviors, distance to health facilities and vector control measures in the Lower Moshi area, northern Tanzania.

Methods: A cross-sectional household survey was carried out, a quantitative method was used to collect information from the households, and the household socio-economic status was estimated by employing a household asset-based approach. The structured questionnaire also collected information on malaria knowledge, attitudes and treatment seeking behaviors.

Results: A total of 197 (68.8\% were female) household heads were interviewed. Distance to the health centers influenced malaria treatment seeking behaviors especially for children $(P=0.001)$ and the number of visits to the health facilities made by the household members $(P=0.001)$. The head of the households' level of education had an influence on bed-net retreatment $(P<0.001)$ and acceptability of larval control programmes $(P<0.001)$. Similarly, a significant association was observed between bed-net retreatment, larval control and occupation of the head of the household.

Conclusion: Distance to the health centre influenced malaria treatment seeking behaviors, and the number of visits made by the household members. In addition, the education level of the household heads played a role in understanding and in the selection of malaria interventions for the households. Increasing the number of health facilities close to rural areas will improve malaria treatment seeking behavior, case management and hence reduce malaria-associated morbidities, especially in high risk groups.
\end{abstract}

\section{Background}

In Sub-Saharan Africa malaria remains a major cause of morbidity and mortality compared to any other region of the world, it is responsible for about 515 million clinical cases and 1.7 million deaths annually [1,2]. The SubSaharan Africa region carries approximately $90 \%$ of the global malaria burden [2]. About 95\% of the Tanzanian population are at risk of malaria and live in areas characterized by stable malaria transmission [3]. In these areas, about 17-20 million clinical episodes of malaria are reported each year and almost 80,000 deaths are attributed to malaria every year $[3,4]$. In rural areas malaria contributes to

\footnotetext{
* Correspondence: asante.kweka@gmail.com

${ }^{1}$ Tanzania Wildlife Research Institute, P.O. Box 661, Arusha, Tanzania

Full list of author information is available at the end of the article
}

approximately $40 \%$ of all outpatient visits; with children under five and pregnant women contributing the highest proportions [5-7]. Currently, there is evidence that malaria transmission is declining in many endemic areas of SubSaharan Africa [3,8-10]. The recent statistics in Tanzania indicate that mortalities due to malaria have decreased from 100,000 [4] to 80,000 deaths [3]. Lower Moshi is considered to be a holo-endemic area for malaria transmission $[11,12]$. Data from health facilities in the area indicate that malaria, upper respiratory infections, soil transmitted helminthes, intestinal protozoa and human immunodeficiency virus infections are the most common health problems [1316]. Similar to the national malaria control strategies, the use of bed nets and treatment of active malaria cases with a dose of effective anti-malarials are the main strategies used

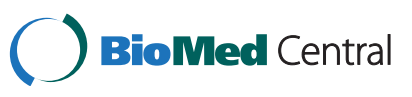


in the area against malaria $[14,17,18]$. The wide distribution of bed nets through subsidized prices, popularly referred to as "hati punguzo", to pregnant women and children under five years old has increased the ownership and protection of these vulnerable groups against malaria [19]. In addition, several intervention trials against malaria that have been conducted in the area have increased the level of bed net ownership and coverage compared to other rural areas in the country [20,21]. Although control efforts have been stepped up in the area, malaria transmission continues to be a public health problem. Findings from previous studies have reported that the majority of individuals were aware of malaria transmission and they used various interventions such as plant repellants to reduce indoor vector density [22]. In addition, the previous studies have reported that the majority of inhabitants could afford to buy treated/nontreated bed nets from local markets [20]. The results from a household-based survey, carried out in Lower Moshi rural communities are reported here. The study focused on understanding how the household social economic status, knowledge, attitude and practice influence malaria treatment seeking behaviors and vector control measures in the Lower Moshi area, northern Tanzania.

\section{Methods}

\section{Study area}

Lower Moshi is located on the southern foothills of Mount Kilimanjaro (321'S, 3721'E) (Figure 1). This area generally has an elevation ranging between 700 to $800 \mathrm{~m}$ above sea level. Malaria transmission occurs throughout the year with low parasitaemia $[14,17,18]$ and low entomological inoculation rate [12,23]. The main malaria vectors in this area are An. arabiensis and An. funestus [12,23-25]. On the land surfaces, several water streams cross the area and form the irrigation channels for paddy (Oryza sativa) irrigation. The rice irrigation schemes have structured and unstructured canal networks; covering an area of about 1,100 hectares. During the rainy season, temporary pools that serve as malaria vector breeding sites are formed. Their persistence beyond the rains contributes to further malaria transmission. The area has two rainy seasons, the long rains which run from March to May and short rainy season from November to December. The average annual rainfall is $900 \mathrm{~mm}$ per year. In addition to paddy cultivation, the inhabitants are also involved in cultivating vegetables, maize (Zea mays), peas (Pisum sativum) and beans (Pisum sativum). Inhabitants also keep domestic animals such as cattle, goats, sheep and poultry.

\section{Study design}

This was an analytical cross-sectional survey, conducted with an objective of determining malaria vectors and larval control knowledge, use and ownership of malaria intervention tools and the wealth of the head of the households. In addition, the study assessed passive malaria cases reported at the health facility within the village and various factors that were associated with the use of malaria intervention tools. The Tropical Pesticides Research Institute distributed bed nets in Lower Moshi for evaluation in 2005 [21]. All selected head of households in this study were involved in the previous bed net distribution and evaluation programme. These nets were not part of free net programmes, which were intended for malaria control for pregnant women and children $[3,26]$. During community surveys a total of 1976 households were visited to characterize their willingness to participate in malaria vector control through a community participatory approach. Thereafter, ten percent (197) of these households were randomly selected to participate in the present study. The head of the household was defined as the person who was perceived by household members to be the primary decision maker in the family; and the household was defined as individuals living together and taking meals from a common cooking facility [27]. In the absence of a household head, a responsible adult above 18 years who was appointed by the family was interviewed.

\section{Data collection}

Data were collected using a structured questionnaire from randomly selected household heads. The data collected included knowledge, attitude and practice (KAP) regarding malaria and integrated malaria control management awareness. The questionnaires also collected information on the distance and cost incurred in visiting the health facilities for malaria treatment. Demographic information of the household heads was also collected. Information on property ownership (radio, bicycle, animals, land, and house light source) was also collected for the purpose of assessing the contribution of wealth on malaria awareness and control. The bed net coverage, treatment and physical status (with or without holes) of bed nets was assessed and related to malaria control knowledge. Data of malaria positive confirmed cases were collected from medical records of the health centre, with the name of patient's village and the period of study when it was conducted. In addition, information on common diseases co-infecting children with malaria in the study area were collected from the health facility records in the study area. The distance from household to nearby health facilities was a factor taken into consideration to characterize community healthseeking behavior.

\section{Data analysis}

Double data entry was done using Microsoft Access for validation purpose before analysis. Statistical analysis was 


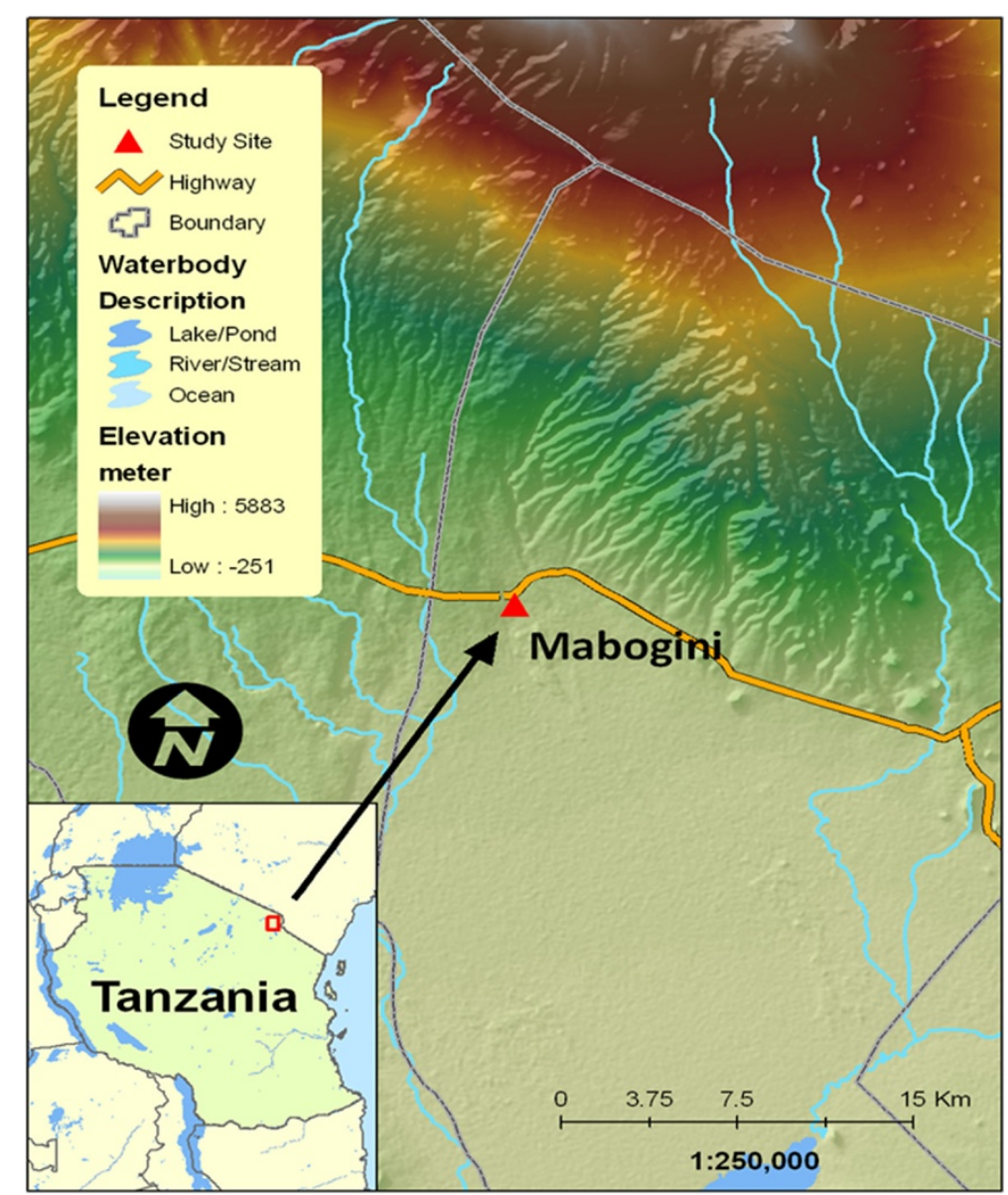

Figure 1 The map of Tanzania showing the area where study was conducted.

done using PWAS statistics 18 (Version 18.0 for Windows, SPSS Inc., Chicago, IL). The effect of distance to the health centre was calculated using a Poisson regression. One way Analysis of Variance (ANOVA) to determine the difference of means between education levels versus ITN ownership; education versus ITN re-treatment, family income and treatment costs coverage. The factor was considered significant when the $P$-value was below 0.05 .

\section{Ethical consideration}

Ethical approval was obtained from The Tropical Pesticides Research Institute ethics committee, Arusha Tanzania prior the commencement of this study. This study was conducted within the main study of the evaluation of bed nets in this area. Permission to conduct the study was also sought from the district authority of the respective study area and from individuals before entering their homes. Meetings were held in each village and the objectives of the study were clearly described to villagers in Kiswahili language, the language inhabitants understood very well. Participants were also informed that participation in the study was on a voluntary basis. Before recruitment into the study, participants were provided with written informed consent; and confidentiality of the all the information collected from households was maintained.

\section{Results}

A total of 197 heads of household were interviewed and their median age was 35.8 (24 to 84 ) years. The majority of the household heads were Christian (53.1\%) and over two thirds of them were females, 68.8\% (136/197). Of all the households, $94.39 \%(185 / 197)$ had primary school education, $8(4.08 \%)$ had secondary school education and the remaining 1.53\% were illiterate. All 197 (100\%) household heads knew about malaria vectors and their role in transmission of malaria. In addition, the household heads had skills and were aware of techniques used to reduce vector-human contact and $80 \%$ of them reported a treatment seeking behaviour for malaria.

On the use of malaria prevention tools, 195 (98.9\%; 95\% CI: 97.01-98.9) of the household heads reported owning and using bed nets for controlling malaria transmission. Among those who reported owning bed nets, 95.4\% (188/ 197; 95\% CI: 94.9 -95.9) owned conventionally treated bed 
nets, and 3.6\% (7/197;; 95\% CI: 2.9-3.9) owned untreated bed nets. A small proportion, 1.0\% (2/197; 95\% CI: $0.85-1.2)$ had no bed nets. None of the studied households reported to own a long lasting insecticide-treated bed net. The wealth of the household heads was also assessed based on equipment owned by the household. The mean household size was 5.3 individuals per household. The average amount of money spent on malaria prevention tools are shown in Table 1 . The mean annual earning of the household heads ranged from 720,000 to 1,440,000 Tanzanian Shillings (516.7 to 1,033.4 USD). In addition, 45.2\% (89/197; 95\% CI: 44.3 - 46.9) of the household heads kept domestic animals in their household. The majority of them kept cattle, goats, sheep and poultry. All of the interviewed household heads were residents of Mabogini for more than 15 years and the majority of them 99.5\% (196/197; 95\% CI: 98.9 - 99.7) knew the areas where malaria vector larvae are found and the time when larvae productivity was high. In fact, the household heads knew that if their houses were close to the mosquito breeding habitats it increased the risk of exposure to mosquito bites and subsequently malaria transmission. The types of houses owned by the household heads varied in design and quality (Figure 2), A total of 811 malaria confirmed cases were found in the health center; of whom $70.28 \%$ (570/811) were children. The distance to the health centre (regarded as a factor for health facility accessibility and cost to be met by patients) significantly influenced malaria treatment seeking behavior among participants (Table 2). Distance to the health centre influenced treatment seeking behaviour for malaria especially for children $(\mathrm{OR}=2.4 ; 95 \% \mathrm{CI}$ : $1.6-2.7, P=0.001)$. No significant association was observed between education level and ownership of bed nets $(\mathrm{F}=1.813, \mathrm{DF}=195, P=0.943)$, mosquito net treatments $(\mathrm{F}=0.258, \mathrm{DF}=195, P=0.773)$, malaria treatment costs $(\mathrm{F}=3.278, \mathrm{DF}=195, P=0.400)$ and family income $(\mathrm{F}=0.869, \mathrm{DF}=193, P=0.421)$. Interestingly, the education level of the household heads was strongly associated with awareness of malaria vector larval control carried out by different authorities $(\mathrm{F}=63.343, \mathrm{DF}=195$, $P>0.001)$ and bed-net re-treatments $(\mathrm{F}=163.362$, $\mathrm{DF}=193, P>0.001)$.

Table 1 The response frequency and cost for mosquito human contact protection outside bed net at household level in lower Moshi per month

\begin{tabular}{lcc}
\hline $\begin{array}{c}\text { Preventive } \\
\text { measure }\end{array}$ & $\begin{array}{c}\text { Response of } \\
\text { household heads }\end{array}$ & $\begin{array}{c}\text { Cost(USD) } \\
\text { /month }\end{array}$ \\
\hline Aerosol spray & $12(6.09 \%)$ & 12.17 \\
\hline Mosquito coils & $99(50.25 \%)$ & 7.57 \\
\hline Synthetic repellents & $2(1.02 \%)$ & 16.45 \\
\hline Use smoke & $143(72.59 \%)$ & 0 \\
\hline Plant base repellents & $164(83.2$ & 0 \\
\hline
\end{tabular}

Note: 1 USD was equivalent to 1680 TShs.
In addition, household head income generating activities showed a significant association with bed-net retreatments $(\mathrm{F}=332.227, \mathrm{DF}=191, P>0.001)$. This was not true for bed net ownership $(\mathrm{F}=1.871, \mathrm{DF}=193$, $P=0.116)$ and food expenditure of household members $(\mathrm{F}=1.578, \mathrm{DF}=193, P=0.209)$. Based on the health reports from the health centre where the majority of the household heads and other community members get their health services, indicates that besides malaria, the area is endemic for other tropical diseases, and coinfections were found to exist (Figure 3).

\section{Discussion}

These findings suggest that distance to the health facility from the household influenced malaria treatment seeking behaviour of most of the household heads. The main groups from the surveyed households, who were negatively affected by the observed distance, were children under five. This observation was similar to reports from previous similar studies [28,29]. Reports from other tropical diseases such as TB and HIV indicated that distance to the health centers were an impending factor for health seeking behaviour and treatments $[19,28]$. From this observation one can speculate that the majority of the household members whose houses are close to the health facilities will have timely and more visits to the health facility as compared to those whose households are far away from the health facility. The further the distance from the health facilities, the higher the cost an individual will incur to visit the health facilities. Despite the distance to the health facilities and the costs, household heads were willing to incur the transport costs for the sick children rather than the adults [29]. In addition, free health services offered to children under five years old, could have contributed to increased visits observed in this age group. To improve malaria treatment seeking behaviors in malaria endemic communities, locating health facilities close to the community or training community health workers may improve malaria treatment seeking behaviors, which could result in early malaria case management and hence reduction of mortality rates associated with malaria in risk groups.

Despite the fact that household income was reasonable as compared to many rural villages [30-32], the annual income had no influence on expenditure for malaria treatment and control. This observation is similar to that of previous studies in malaria endemic countries [26,33]. However, this contrasts with findings of other similar studies in malaria endemic areas [26,33]. Probably, the free bed net distribution policy for children and pregnant women has resulted in money spent on bed nets at the household level to be low $[3,4,26,34]$ Bed nets are one of the most recognized methods of personal protection against mosquitoes, and many studies have reported 


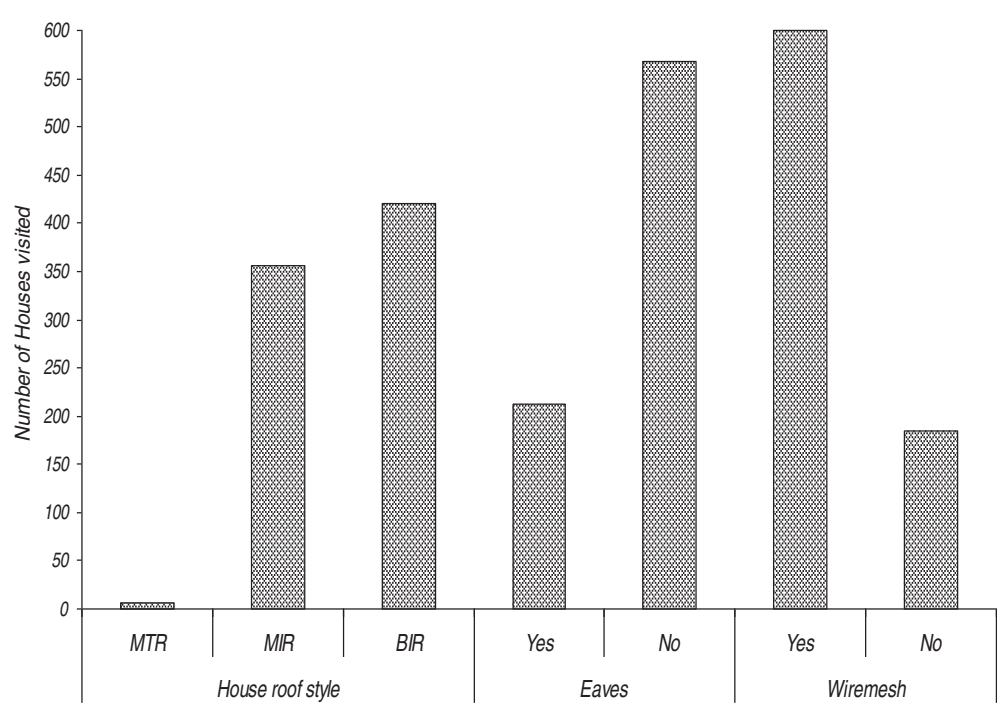

Figure 2 The house characteristics and improvements in area of lower Moshi irrigation scheme, House styles; Mud wall and thatches roof (MTR), Mud wall and Iron roof (MIR), Brick wall and Iron roof (BIR) and presence or Absence of eaves and wire mesh.

the benefits of bed nets; either insecticide treated or untreated $[35,36]$. In the study area, like many other areas in the country [20], use of conventional insecticidetreated bed nets was the most common protection tool for malaria. Despite the majority of households reporting to own treated bed nets, a significant number did not re-treat their bed nets at the recommended time. Thus, most of the bed nets become less protective against mosquitoes and increase the risk of malaria transmission. Net washing is an important determinant of the effectiveness of ITNs [37], and targeted efforts have to be made to sensitize the community on washing their nets after a specified period of time. A small proportion of households were observed to have untreated bed nets and others had no bed nets. Of the households visited, none owned long lasting insecticide-treated bed nets. The observation was similar to previous findings in four other villages in rural Tanzania where the bed net coverage was low and associated with high rates of malaria transmission [20].
The main malaria vectors found in the area are, $A n$. arabiensis and more currently An. gambiae s.s has also been recorded [12,28,38]. The former species is known to be zoophilic (feeds on mammals such as cattle) and anthropophilic depending on the type of host available and geographical locations $[39,40]$. The presence of cattle in the households may attract additional mosquitoes to the household vicinity, resulting in zoopotentiation. Entomological studies in the same area have demonstrated that $A n$. arabiensis had higher preference to animal baits rather than human being baits and odourbaited traps [25]. Conversely, use of cow urine showed similar results on behavioral response of An. arabiensis $[41,42]$. For the households without animals in their compounds, human beings are most likely to be the blood meal source than their counterparts with cattle herds [43]. From these observations, the use of ITNs or LLITNs for protection against anthropophilic mosquito species is recommended. For the zoophilic species (which bites outdoors), use of pyrethroid insecticides

Table 2 Health care centre visiting rates among the residents interviewed in lower Moshi living at a distance of 0 to $6.0 \mathrm{Km}$ from the health centre

\begin{tabular}{lcc}
$\begin{array}{c}\text { Distance } \\
\text { (In kilometer) }\end{array}$ & $\begin{array}{c}\text { Number of patients who } \\
\text { attended the clinic } \\
\text { (by distance) }\end{array}$ & $\begin{array}{c}\text { Rate of clinic visits by distance lived } \\
\text { from clinic/person/year } \\
(\mathbf{9 5} \% \mathbf{C l})\end{array}$ \\
\hline $0.0-1.0$ & 224 & $0.28(0.24,0.33)$ \\
\hline $1.01-2.0$ & 112 & $0.14(0.11,0.18)$ \\
\hline $2.01-3.0$ & 24 & $0.03(0.02,0.05)$ \\
\hline $3.01-4.0$ & 16 & $0.02(0.01,0.03)$ \\
\hline $4.01-5.0$ & 396 & $0.37,0.7)$ \\
\hline $5.01-6.0$ & 12 & $0.05(0.05,0.07)$ \\
\hline Overall & DF $=195$ & $0.02(0.01,0.03)$ \\
\hline
\end{tabular}




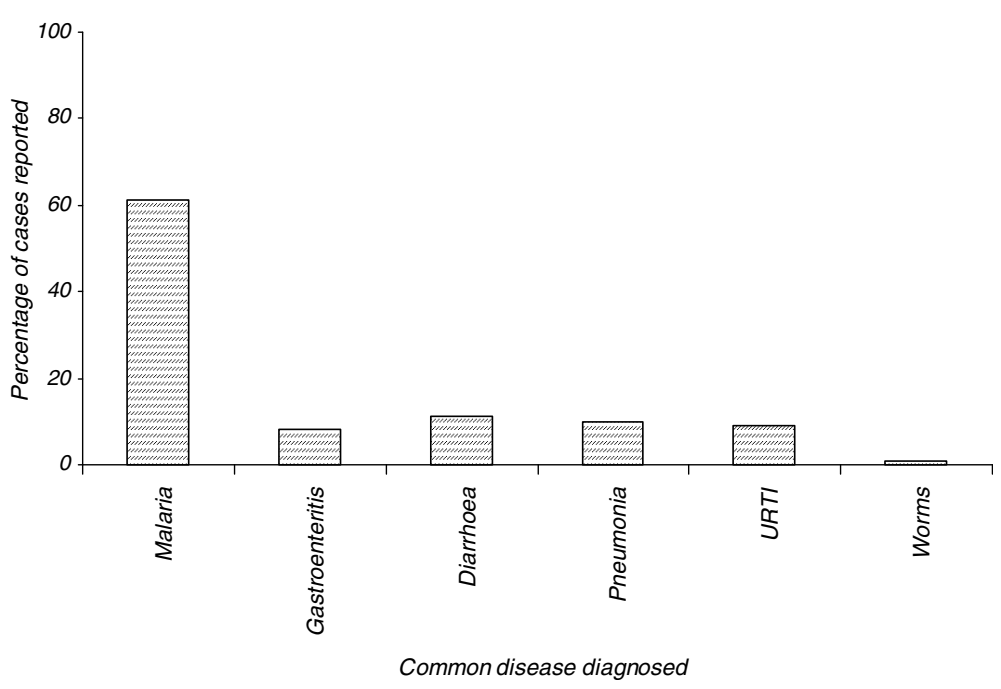

Figure 3 The commonly diagnosed diseases at Lower Moshi health facility for children under five years old.

sprayed on animals for the households with animals, may serve to reduce mosquito density in their vicinities. Use of topical repellants is also recommended for households with or without animals in their vicinity. In addition, the paddy irrigation scheme in the area is another potential risk factor for malaria transmission as it provides breeding sites for malaria vectors throughout the year [24,38,44-48]. Thus, more integrated efforts against malaria are highly required in the area. Individuals with higher education were more health conscious and more likely to adhere to public health education as compared to illiterate people. In our study, a high education level was significantly associated with bed-net retreatment among the study participants. These findings are supported by the findings of other studies in different epidemiological settings where malaria is endemic [33,49-51]. Similarly, in the same study population, education level was associated with good awareness of the larval control strategies for reduction of malaria transmission. Surprisingly, there was no relationship between the education level of the household heads and ownership of bed nets. Our observation was contrary to previous observations where the household head's education level was reported to be significantly associated with bed net ownership and re-treatments [33,35].

Similar to other community studies, individuals with a higher income have a positive response to public health intervention for many tropical diseases, including malaria [33]. Despite having a reasonable income to support the family members in buying ITNs and insecticides for bed-net re-treatment from the retail markets, the majority of the household heads did not adhere to utility and re-treatment of bed nets. Similar findings were reported in Western Kenya [52]. Furthermore, no association was observed between the level of bed net ownership and the household income. The distribution of subsidized ITNs among pregnant women and children under five through the "Hati Punguzo" programme and the ongoing mass distribution of free ITNs from the government have increased the coverage and ownership in the community $[9,20]$. However, despite these individuals having a reasonable income, the majority of the household heads did not adhere to bed-net usage or bed-net retreatment. The favorable environment for vector survival and high prevalence of tropical diseases in SubSaharan Africa, means that co-infections of multiple parasitic infections in an area or in a single host are common [52,53]. The multiple parasitic infections are associated with considerable morbidities in co-infected individuals [53]. In fact, co-infections of malaria and other diseases such as helminth infections tend to potentiate the effects of each other in a co-infected individual [53-55]. In addition to malaria, other diseases found prevalent amongst children in the study area were pneumonia, diarrhea, upper respiratory tract infection (URTI), gastroenteritis and intestinal helminths. Because of high prevalence of these infections, co-infections are possible. The cost spent on personal protection measures when outside the bed net at household level might have been another factor for persistence of malaria transmission in the study area, as few are protected by other means outside the bed nets. The house improvements in this study area should target the blocking of eaves, and the use of window screens among the residents, which have been reported to have great impact in other areas for reducing indoor malaria transmission [52,56-59]. Environmental management for larval control has played a major role in malaria vector reduction 
and elimination in different areas where the technique was deployed [59-65]; hence it has to be considered in the present study area for the larval habitat control in irrigation schemes and in other habitat types, since community members are knowledgeable about mosquito habitats. Currently, there is loss of efficacy in pyrethroids used in ITN and IRS programs against malaria vectors $[66,67]$. In this study area, most malaria vectors have been reported to be resistant against the pyrethroids used in public health $[11,68]$. Understanding continuous malaria transmission in this area remains a major factor. Malaria vector control tools have been implemented for a while in this community and seemed to lose efficacy in other parts of malaria endemic regions [66,67]. The commonly reported factor from the community is the lack of knowledge on loss of efficacy of the conventionally treated bed nets after a given period of time and numbers of washes, hence allowing mosquito feeding success and subsequently disease transmission. The findings from the current study suggest that community members in the study area can afford to buy LLITNs but seem to have lacked motivation in the importance of using LLITNs to substitute ITNs, which are not regularly re-treated as described by public health officials for best protection outcomes. Education and occupation had an influence in vector control tools, therefore, knowledge and utility might have more impact on bed net effect for wide community protection either provided for free or under subsidized price [35,69,70]. In malaria-endemic parts of western Kenya and Ghana, studies have found that, the nets offered to pregnant mothers and infants during clinics visits do not mean utility for personal protection as many people own bed nets but do not use them [35,71].

\section{Conclusion}

Distance to the health centre influenced malaria treatment seeking behaviors and the number of visits made by the household members. In addition, the education level of the household heads played a role in understanding and selecting malaria interventions for the household. Thus, locating health facilities or training and employing community health workers who will work with the endemic communities may improve malaria treatment seeking behavior, case management and hence reduce malaria associated morbidities, especially in high risk groups.

Education level of the household heads had a significant association with malaria treatment seeking behavior, bed net ownership and retreatment. The distance to the health facility significantly influenced the decision of the household heads to seek malaria treatment, especially for children. There is an urgent need for additional health officials and infrastructure in rural areas to be implemented by the Tanzania government.

\section{Competing interest}

The authors have declared that no competing interests exist.

\section{Acknowledgments}

The authors are grateful to the TPRI for funding the study and Mabogini field station staffs for their invaluable support during the field surveys and subsequent data collections and cleaning. We thank Charles P. Massenga, Mrs. Kisanga and Augustine Mtui for community preparation for this study, questionnaire distribution and dispensing. We thank Hazel McCullough from The London School of Hygiene and Tropical Medicine for English language editing.

\section{Author details}

${ }^{1}$ Tanzania Wildlife Research Institute, P.O. Box 661, Arusha, Tanzania. 2Department of Medical Parasitology and Entomology, Catholic University of Health and Allied Sciences, P.O. Box 1464, Mwanza, Tanzania. ${ }^{3}$ Tropical Pesticides Research Institute, Division of Livestock and Human Disease Vector Control, Mosquito Section, P.O. Box 3024, Arusha, Tanzania. ${ }^{4}$ KCM College of Tumaini University, P.O. Box 2240, Moshi, Tanzania. ${ }^{5}$ Department of Physical Sciences, Faculty of Science, Sokoine University of Agriculture, P. O. Box 3038, Chuo Kikuu - Morogoro, Tanzania.

\section{Authors' contributions}

$A L$ and EJK conceived and designed the study. AL, SM MJM, AMM, BJM, HDM, EEK performed the field work. AL, BJM, EEM and AMM analyzed the data: AL, EE, HDM and EJK wrote the paper. All authors reviewed and accepted the final version for submission.

Received: 26 May 2011 Accepted: 28 June 2012

Published: 28 June 2012

\section{References}

1. Snow RW, Guerra CA, Noor AM, Myint HY, Hay SI: The global distribution of clinical episodes of Plasmodium falciparum malaria. Nature 2005, 434:214-217.

2. Greenwood B, Mutabingwa T: Malaria in 2002. Nature 2002, 415:670-672.

3. Ministry of Health and Social Welfare: National malaria control medium term malaria strategic plan, February 2008 - January 2013. Tanzania: Dar Es Salaam; 2008.

4. Ministry of Health: National Malaria Medium-term Strategic Plan, July 2002-June 2006. Tanzania: Dar Es Salaam; 2002.

5. Tuba M, Sandoy IF, Bloch P, Byskov J: Fairness and legitimacy of decisions during delivery of malaria services and ITN interventions in zambia. Malaria $J$ 2010, 9:309.

6. Mboera LE, Makundi EA, Kitua AY: Uncertainty in malaria control in Tanzania: crossroads and challenges for future interventions. Am J Trop Med Hyg 2007, 77:112-118.

7. Bhattarai A, Ali AS, Kachur SP, Martensson A, Abbas AK, Khatib R, Al-Mafazy AW, Ramsan M, Rotllant G, Gerstenmaier JF, et al: Impact of artemisinin-based combination therapy and insecticide-treated nets on malaria burden in Zanzibar. PLoS Med 2007, 4:e309.

8. Aregawi MW, Ali AS, Al-Mafazy AW, Molteni F, Katikiti S, Warsame M, Njau R, Komatsu R, Korenromp E, Hosseini M, et al: Reductions in malaria and anaemia case and death burden at hospitals following scale-up of malaria control in Zanzibar, 1999-2008. Malaria J 2011, 10:46.

9. Okiro EA, Hay SI, Gikandi PW, Sharif SK, Noor AM, Peshu N, Marsh K, Snow RW: The decline in paediatric malaria admissions on the coast of Kenya. Malar J 2007, 6:151.

10. O'Meara WP, Mangeni JN, Steketee R, Greenwood B: Changes in the burden of malaria in sub-Saharan Africa. Lancet Infect Dis 2010, 10:545-555.

11. Kulkarni MA, Rowland M, Alifrangis M, Mosha FW, Matowo J, Malima R, Peter J, Kweka E, Lyimo I, Magesa S, et al: Occurrence of the leucine-to-phenylalanine knockdown resistance $(\mathrm{kdr})$ mutation in Anopheles arabiensis populations in Tanzania, detected by a simplified high-throughput SSOP-ELISA method. Malaria J 2006, 5:56.

12. Mahande A, Matias JR, Dusfour I, Kweka EJ: Knock-down resistance, rdl alleles and the annual entomological inoculation rate of wild mosquito populations from lower Moshi, Northern Tanzania. J Global Infect Dis 2012, 4:114-119.

13. Falnes EF, Tylleskar T, de Paoli MM, Manongi R, Engebretsen IM: Mothers' knowledge and utilization of prevention of mother to child transmission services in northern Tanzania. J. Intern AIDS Soc 2010, 13:36. 
14. Kweka EJ, Lowassa A, Msangi S, Kimaro EE, Lyatuu EE, Mwang'onde BJ, Mahande AM, Mazigo HD: Low sensitivity of ParaHIT-f rapid malaria test among patients with fever in rural health centers, Northern Tanzania. J. infect dev countr 2011, 5:204-208.

15. Siza JE: Risk factors associated with low birth weight of neonates among pregnant women attending a referral hospital in northern Tanzania. Tanzania J health research 2008, 10:1-8.

16. van den Boogaard J, Lyimo R, Irongo CF, Boeree MJ, Schaalma $H$, Aarnoutse RE, Kibiki GS: Community vs. facility-based directly observed treatment for tuberculosis in Tanzania's Kilimanjaro Region. Int J Tuberc Lung Dis 2009, 13:1524-1529.

17. Shekalaghe S, Alifrangis M, Mwanziva C, Enevold A, Mwakalinga S, Mkali H, Kavishe R, Manjurano A, Sauerwein R, Drakeley C, et al: Low density parasitaemia, red blood cell polymorphisms and Plasmodium falciparum specific immune responses in a low endemic area in northern Tanzania. BMC Infect Dis 2009, 9:69.

18. Shekalaghe SA, Bousema JT, Kunei KK, Lushino P, Masokoto A, Wolters LR, Mwakalinga S, Mosha FW, Sauerwein RW, Drakeley CJ: Submicroscopic Plasmodium falciparum gametocyte carriage is common in an area of low and seasonal transmission in Tanzania. Trop Med Int Health 2007, 12:547-553.

19. Mulligan JA, Yukich J, Hanson K: Costs and effects of the Tanzanian national voucher scheme for insecticide-treated nets. Malaria J 2008, 7:32.

20. Kweka EJ, Nkya WM, Mahande AM, Assenga C, Mosha FW, Lyatuu EE, Massenga CP, Nyale EM, Mwakalinga SB, Lowassa A: Mosquito abundance, bed net coverage and other factors associated with variations in sporozoite infectivity rates in four villages of rural Tanzania. Malaria J 2008, 7:59.

21. Msangi S, Lyatuu E, Masenga C, Kihumo E: The effects of washing and duration of use of long-lasting insecticidal nets (PermaNets) on insecticidal effectiveness. Acta Trop 2008, 107:43-47

22. Kweka EJ, Mosha F, Lowassa A, Mahande AM, Kitau J, Matowo J, Mahande MJ, Massenga CP, Tenu F, Feston E, et al: Ethnobotanical study of some of mosquito repellent plants in north-eastern Tanzania. Malaria J 2008, 7:152.

23. Kulkarni MA, Kweka E, Nyale E, Lyatuu E, Mosha FW, Chandramohan D, Rau ME, Drakeley C: Entomological evaluation of malaria vectors at different altitudes in Hai district, northeastern Tanzania. J Med Entomol 2006, 43:580-588.

24. ljumba JN, Shenton FC, Clarke SE, Mosha FW, Lindsay SW: Irrigated crop production is associated with less malaria than traditional agricultural practices in Tanzania. Trans R Soc Trop Med Hyg 2002, 96:476-480.

25. Mahande A, Mosha F, Mahande J, Kweka E: Feeding and resting behaviour of malaria vector, Anopheles arabiensis with reference to zooprophylaxis. Malaria 2007, 6:100.

26. Ahmed SM, Haque R, Haque U, Hossain A: Knowledge on the transmission, prevention and treatment of malaria among two endemic populations of Bangladesh and their health-seeking behaviour. Malaria J 2009, 8:173.

27. Talisuna A, Grewal P, Rwakimari JB, Mukasa S, Jagoe G, Banerji J: Cost is killing patients: subsidising effective antimalarials. Lancet 2009,

374:1224-1226

28. Mshana GH, Wamoyi J, Busza J, Zaba B, Changalucha J, Kalurya S, Urassa M: Barriers to accessing antiretroviral therapy in Kisesa, Tanzania: a qualitative study of early rural referrals to the national program. AIDS Patient Care STDS 2006, 20:649-657.

29. Hardon AP, Akurut D, Comoro C, Ekezie C, Irunde HF, Gerrits T, Kglatwane J, Kinsman J, Kwasa R, Maridadi J, et al: Hunger, waiting time and transport costs: time to confront challenges to ART adherence in Africa. AIDS Care 2007, 19:658-665.

30. Schellenberg JA, Victora CG, Mushi A, de Savigny D, Schellenberg D, Mshinda $H$, Bryce J: Inequities among the very poor: health care for children in rural southern Tanzania. Lancet 2003, 361:561-566.

31. Kakwani NA, Wagstaff A, Van Doorslaer E: Socio economic inequalities in health: measurement, computation and statistical inference. J Econ 1997, 77:87-103.

32. Bonnila-Chagin M, Hammer SJ: Life and death amongst the poor. Washington, DC: The Johns Hopkins University and Development Economics Research Group/The World Bank; 1999.

33. Goesch JN, Schwarz NG, Decker ML, Oyakhirome S, Borchert LB, Kombila UD, Poetschke M, Lell B, Issifou S, Kremsner PG, et al: Socio-economic status is inversely related to bed net use in Gabon. Malaria J 2008, 7:60.
34. Magesa SM, Lengeler C, de Savigny D, Miller JE, Njau RJ, Kramer K, Kitua A, Mwita A: Creating an "enabling environment" for taking insecticide treated nets to national scale: the Tanzanian experience. Malaria J 2005, 4:34.

35. Atieli HE, Zhou G, Afrane Y, Lee MC, Mwanzo I, Githeko AK, Yan G: Insecticide-treated net (ITN) ownership, usage, and malaria transmission in the highlands of western Kenya. Parasit Vectors 2011, 4:113.

36. Chukwuocha UM, Dozie IN, Onwuliri CO, Ukaga CN, Nwoke BE, Nwankwo BO, Nwoke EA, Nwaokoro JC, Nwoga KS, Udujih OG, et al: Perceptions on the use of insecticide treated nets in parts of the Imo River Basin, Nigeria: implications for preventing malaria in pregnancy. Afr J Reprod Health 2010, 14:117-128.

37. Atieli FK, Munga SO, Ofulla AV, Vulule JM: Wash durability and optimal drying regimen of four brands of long-lasting insecticide-treated nets after repeated washing under tropical conditions. Malaria J 2010, 9:248.

38. ljumba JN, Mosha FW, Lindsay SW: Malaria transmission risk variations derived from different agricultural practices in an irrigated area of northern Tanzania. J. Med Vet Entomol 2002, 16:28-38.

39. Coetzee M: Distribution of the African malaria vectors of the Anopheles gambiae complex. Am J Trop Med Hyg 2004, 70:103-104.

40. Coetzee M, Craig M, le Sueur D: Distribution of African malaria mosquitoes belonging to the Anopheles gambiae complex. Parasitol Today 2000, 16:74-77.

41. Kweka EJ, Mwang'onde BJ, Mahande AM: Optimization of odour-baited resting boxes for sampling malaria vector, Anopheles arabiensis Patton, in arid and highland areas of Africa. Parasit Vectors 2010, 3:75.

42. Mahande AM, Mosha FW, Mahande JM, Kweka EJ: Role of cattle treated with deltamethrine in areas with a high population of Anopheles arabiensis in Moshi. Northern Tanzania. Malaria J 2007, 6:109.

43. Kweka EJ, Mwang'onde BJ, Kimaro E, Msangi S, Massenga CP, Mahande AM: A resting box for outdoor sampling of adult Anopheles arabiensis in rice irrigation schemes of lower Moshi, northern Tanzania. Malaria J 2009, 8:82.

44. Baeza A, Bouma MJ, Dobson AP, Dhiman R, Srivastava HC, Pascual M: Climate forcing and desert malaria: the effect of irrigation. Malaria J 2011, 10:190.

45. Ijumba JN, Lindsay SW: Impact of irrigation on malaria in Africa: paddies paradox. Med Vet Entomol 2001, 15:1-11.

46. Ijumba JN, Mwangi RW, Beier JC: Malaria transmission potential of Anopheles mosquitoes in the Mwea-Tebere irrigation scheme, Kenya. Med Vet Entomol 1990, 4:425-432

47. Kenea O, Balkew M, Gebre-Michael T: Environmental factors associated with larval habitats of anopheline mosquitoes (Diptera: Culicidae) in irrigation and major drainage areas in the middle course of the Rift Valley, central Ethiopia. J Vector Borne Dis 2011, 48:85-92.

48. Panigrahi BK, Kerketta AS, Mohapatra A, Hazra RK, Parida SK, Marai NS, Kar SK, Mahapatra N: Effect of construction of an irrigation canal on malaria situation in two primary health centres of Dhenkanal district of Orissa, India. Trop Biomed 2011, 28:76-84.

49. Sanjana P, Barcus MJ, Bangs MJ, Ompusunggu S, Elyazar I, Marwoto $H$, Tuti S, Sururi M, Tjokrosonto S, Baird JK: Survey of community knowledge, attitudes, and practices during a malaria epidemic in central Java. Indonesia. Am. J Trop Med Hyg 2006, 75:783-789.

50. Pettifor A, Taylor E, Nku D, Duvall S, Tabala M, Meshnick S, Behets F: Bed net ownership, use and perceptions among women seeking antenatal care in Kinshasa, Democratic Republic of the Congo (DRC): opportunities for improved maternal and child health. BMC Public Health 2008, 8:331.

51. Ng'ang'a PN, Jayasinghe G, Kimani V, Shililu J, Kabutha C, Kabuage L, Githure J, Mutero C: Bed net use and associated factors in a rice farming community in Central Kenya. Malaria J 2009, 8:64.

52. Utzinger J, Tozan $Y$, Singer BH: Efficacy and cost-effectiveness of environmental management for malaria control. Trop Med Int Health 2001, 6:677-687.

53. Mboera LE, Senkoro KP, Rumisha SF, Mayala BK, Shayo EH, Mlozi MR: Plasmodium falciparum and helminth coinfections among schoolchildren in relation to agro-ecosystems in Mvomero District, Tanzania. Acta Trop 2011, 120:95-102.

54. Yamamoto S, Louis VR, Sie A, Sauerborn R: Household risk factors for clinical malaria in a semi-urban area of Burkina Faso: a case-control study. Trans R/ Soc Trop Med Hyg 2011, 104:61-65. 
55. Mazigo HD, Waihenya R, Lwambo NJ, Mnyone LL, Mahande AM, Seni J, Zinga M, Kapesa A, Kweka EJ, Mshana SE, et al: Co-infections with Plasmodium falciparum. Schistosoma mansoni and intestinal helminths among schoolchildren in endemic areas of northwestern Tanzania. Parasit Vectors 2010, 3:44.

56. Mazigo H, Ambrose EE, Zinga M, Bahemana E, Mnyone LL, Kweka EJ, Heukelbach J: Prevalence of intestinal parasitic infections among patients attending Bugando Medical Centre in Mwanza, north-western Tanzania: a retrospective study. Tanzania J Health Res 2010, 12:202-207.

57. Kirby MJ, Ameh D, Bottomley C, Green C, Jawara M, Milligan PJ, Snell PC, Conway DJ, Lindsay SW: Effect of two different house screening interventions on exposure to malaria vectors and on anaemia in children in The Gambia: a randomised controlled trial. Lancet 2009, 374:998-1009.

58. Atieli H, Menya D, Githeko A, Scott T: House design modifications reduce indoor resting malaria vector densities in rice irrigation scheme area in western Kenya. Malaria J 2009, 8:108.

59. Garrett-Jones C: The human blood index of malaria vectors in relation to epidemiological assessment. Bull World Health Organ 1964, 30:241-261.

60. Fillinger U, Kannady K, William G, Vanek MJ, Dongus S, Nyika D, Geissbuhler Y, Chaki PP, Govella NJ, Mathenge EM, et al: A tool box for operational mosquito larval control: preliminary results and early lessons from the Urban Malaria Control Programme in Dar es Salaam. Tanzania. Malaria J 2008, 7:20.

61. Fillinger $U$, Knols BG, Becker N: Efficacy and efficiency of new Bacillus thuringiensis var israelensis and Bacillus sphaericus formulations against Afrotropical anophelines in Western Kenya. Trop Med Int Health 2003, 8:37-47.

62. Fillinger U, Ndenga B, Githeko A, Lindsay SW: Integrated malaria vector control with microbial larvicides and insecticide-treated nets in western Kenya: a controlled trial. Bull World Health Organ 2009, 87:655-665.

63. Fillinger U, Sombroek H, Majambere S, van Loon E, Takken W, Lindsay SW: Identifying the most productive breeding sites for malaria mosquitoes in The Gambia. Malaria J 2009, 8:62

64. Imbahale SS, Fillinger U, Githeko A, Mukabana WR, Takken W: An exploratory survey of malaria prevalence and people's knowledge, attitudes and practices of mosquito larval source management for malaria control in western Kenya. Acta Trop 2010, 115:248-2

65. Imbahale SS, Mweresa CK, Takken W, Mukabana WR: Development of environmental tools for anopheline larval control. Parasit Vectors 2011, 4:130.

66. N'Guessan R, Corbel V, Akogbeto M, Rowland M: Reduced efficacy of insecticide-treated nets and indoor residual spraying for malaria control in pyrethroid resistance area, Benin. Emerging infect dis 2007, 13:199-206.

67. Trape JF, Tall A, Diagne N, Ndiath O, Ly AB, Faye J, Dieye-Ba F, Roucher C, Bouganali C, Badiane A, et al: Malaria morbidity and pyrethroid resistance after the introduction of insecticide-treated bednets and artemisinin-based combination therapies: a longitudinal study. Lancet Infect Dis 2011, 11:925-932.

68. Matowo J, Kulkarni MA, Mosha FW, Oxborough RM, Kitau JA, Tenu F, Rowland M: Biochemical basis of permethrin resistance in Anopheles arabiensis from Lower Moshi, north-eastern Tanzania. Malaria J 2010, 9:193.

69. Maxwell CA, Msuya E, Sudi M, Njunwa KJ, Carneiro IA, Curtis CF: Effect of community-wide use of insecticide-treated nets for 3-4 years on malarial morbidity in Tanzania. Trop Med Int Health 2002, 7:1003-1008.

70. Maxwell CA, Rwegoshora RT, Magesa SM, Curtis CF: Comparison of coverage with insecticide-treated nets in a Tanzanian town and villages where nets and insecticide are either marketed or provided free of charge. Malaria J 2006, 5:44.

71. Baume CA, Koh ACF: Predictors of mosquito net use in Ghana. Malaria J 2011, 10:265.

doi:10.1186/1756-3305-5-129

Cite this article as: Lowassa et al: Social economic factors and malaria transmission in Lower Moshi, Northern Tanzania. Parasites \& Vectors 2012 5:129.

\section{Submit your next manuscript to BioMed Central and take full advantage of:}

- Convenient online submission

- Thorough peer review

- No space constraints or color figure charges

- Immediate publication on acceptance

- Inclusion in PubMed, CAS, Scopus and Google Scholar

- Research which is freely available for redistribution 